\title{
Etiologies of the Hearing Loss and Their Impacts at the Patients Worn Hearing Aid in the International Center of Hearing Correction in Abidjan (ICHC)
}

\author{
Mobio N'kan Max Ange, Ille Salha, Yavo-Dosso Nadine, Yotio Ayekpa, D. Nasser, \\ Yapo Assi Romaric Evrand, V. Koffi-Aka
}

Service d'ORL et de Chirurgie Cervicofacial (CC-F), CHU Treichville, Abidjan, Côte d'Ivoire

Email: mobiomax@yahoo.fr, ille_salha07@yahoo.fr,yavonadine@yahoo.fr

How to cite this paper: Ange, M.N.M., Salha, I., Nadine, Y.-D., Ayekpa, Y., Nasser, D., Evrand, Y.A.R. and Koffi-Aka, V. (2018) Etiologies of the Hearing Loss and Their Impacts at the Patients Worn Hearing Aid in the International Center of Hearing Correction in Abidjan (ICHC). International Journal of Otolaryngology and Head \& Neck Surgery, 7, 359-366.

https://doi.org/10.4236/ijohns.2018.76036

Received: August 29, 2018

Accepted: November 11, 2018

Published: November 14, 2018

Copyright $\odot 2018$ by authors and Scientific Research Publishing Inc. This work is licensed under the Creative Commons Attribution International License (CC BY 4.0).

http://creativecommons.org/licenses/by/4.0/

\begin{abstract}
Objective: Determine the etiologies and their impacts of hearing loss at the patients' worn hearing aid in the international center of hearing correction in Abidjan (ICHC). Material and Method: The study is of transverse and analytical type realized in the ICHC from July 1999 to June 2010. It concerned the files of patients' worn hearing aid in the center. The patients worn initially in another center but followed in the ICHC were excluded. Data were collected from medical files of patients and concerned etiologies, age, type, degree of hearing loss as well as the prosthetic gains and the satisfaction. Results: Fifteen etiologies were listed with in first three rows the meningitis (17.9\%) the presbyacusis $(17.5 \%)$ and chronic otitis media (12.1\%). The degrees of hearing loss in the seven etiologies most frequent were severe and profound in $87.6 \%$ of cases to the right and $82.8 \%$ to the left. The prosthetic pure tonal gain was significant in case of sound trauma and sudden hearing loss. The prosthetic speech reception threshold gain was only significant in case of presbyacusis and sudden hearing loss. The satisfaction of hearing aids was significant in case of presbyacusis, sudden hearing loss and the sound trauma. Conclusion: The main clauses etiologies were the meningitis and the presbyacusis. The tonal and speech prosthetic gain were significant in case of sudden hearing loss.
\end{abstract}

\section{Keywords}

Etiologies, Hearing Loss, Hearing Aid, Satisfaction

\section{Introduction}

The hearing aid is one of the first technical and therapeutics progress allowing 
managing the hearing loss. This hearing impairment is a social handicap. Three hundred and fifty million of people in the world or $7 \%$ of the world population are affected by hearing disorders according to the WHO [1]. Only $20 \%$ of these patients have hoped to improve their hearing acuteness by medical and surgical means to restore the biological mechanism of the hearing. The other patients can only satisfy themselves with a hearing aid [2]. This hearing loss can only be tied to ear disease or a part of a general disease. In the latter case, the hearing aid can be the only one of the means of care. So it is possible to prevent some etiologies. According to Luzia in the city of Salvador state of Bahia (Brasilia), the main responsible etiological factor for hearing loss in the evaluated population (53 children and adolescents) was maternal rubella, amounting to $32 \%$ of the cases of hearing loss, followed by pyogenic meningitis with $20 \%$. Otitis media represented $4 \%$ and ototoxicity $2 \%$. Bilateral sensorineural hearing impairment was presented by $62 \%$ of the population. Thirty subjects $(56 \%)$ had profound hearing loss. The hearing aid device was worn by $58 \%$ population [3]. The hearing loss can decrease the ability to communicate. Research has indicated the existence of a critical period that occurs within the first years of a child's life for speech acquisition. Lack of proper auditory stimulation in childhood may preclude the complete development and maturation of central auditory pathways [4]. In Ivory Coast, there is no data work concerning the etiologies of hearing loss at the patients worn. That study allows a screening indication of hearing aid or orientation to cochlear implant according to our practice. That motivated this work to determine the etiologies of hearing loss and their impact at the patients worn.

\section{Patients and Method}

This is a transverse and analytical study realized in the International Center of Hearing Correction (ICHC) from July 1999 to June 2010 or a period of 10 years. It concerned patient worn hearing aid in this center, all age and sex, regularly followed, evaluated in relation with prosthetic pure tonal gain, prosthetic speech reception threshold gain and satisfaction. The following prosthetic was made in the first month and all the fourth month during the first year. Above the first year, the control was achieved according the patient's need. The prosthetic evaluation was updated at each control. Patients worn in another center and secondarily followed in the ICHC for adjustment problem or maintenance of their hearing aid were excluded. Data collection was performed using an index card of investigation according to the medical files of patients. The studies parameters were etiologies, age, type of hearing loss, degree of hearing loss, the prosthetic pure tonal gain, the prosthetic speech reception threshold gain and the satisfaction of the patient. These parameters were obtained from the medical files kept in ICHC and updated after each control. The degree of hearing loss was determined according to the classification of International Bureau of Audio Phonology, from the average hearing loss (BIAP) [5]. The prosthetic pure tonal gain was the difference between the (tonal) hearing threshold in not worn ear and the 
(tonal) hearing threshold in worn ear [6]. The prosthetic speech reception threshold gain was the difference between the vocal comprehensibility threshold in not worn ear and in worn ear. It was determine from the curve of comprehensibility by measuring in decibel on the axis of orderly of $50 \%$, the distance which separates the curve pathological (not worn ear) of the curve worn ear [6]. The level of satisfaction was obtained from the following information: advice of use. Appreciation on the device quality, clarity, sound sensation, adaptation to the sound environment, easy in use of the device, assessment of achieved result with the device, conversation in quiet environment, listen to the television, use of phone, satisfaction of patient's people, occasional whistling (Larsen effect), conversation in noisy environment, conversation in car, conversation in group time to bear of devices, frequency of renewals of battery. This information was noted on a scale as follow: $0=$ not satisfied; $1=$ little satisfied, $2=$ satisfied. Then the total of point was made. It allowed stratifying patient into:

Satisfied (3/3 - 2/3 of total point), little satisfied (1/3-2/3 of total point) and not satisfied ( $0-1 / 3$ of total point).

The index card of investigation were exploited and analyzed on the software (EPI INFO) a statistical connection was made between different etiologies and age by means of the test KHI SQUARE of PEARSON. Also this test was used to determine the influence of these etiologies on the prosthetic pure tonal gain, the prosthetic speech reception threshold gain and the satisfaction of the patient. The threshold signification for this test was established in 5\%. The ethical considerations have been approved by ethics and compliance committee.

\section{Results}

536 patients were listed. We noticed 329 men and 207 women, that is a sex-ratio of 1.5. The average age of the patient was 36 years (extreme: 2 and 92 years) with a standard deviation \pm 23 . 94 . The children were among $134 \%$ or $25 \%$ of cases. In $69 \%$ of cases $(n=370)$ behind the ear hearing aids were used, intra-auricular hearing aids in $29.5 \%$ of cases $(n=158)$ and hearing glasses in $15 \%$ of cases. The hearing aid was bilateral in $62.7 \%$ of cases $(\mathrm{n}=336)$ and unilateral in $37.3 \%$ of cases ( $\mathrm{n}=200$ with 160 cases of bilateral hearing loss). Fifteen etiologies were observed. The meningitis in $17.9 \%$ of cases, the presbyacusis in $17.5 \%$ of cases and the chronic otitis media in $12.1 \%$ (Figure 1). For the comparative analysis, there are seven etiologies most frequent which were selected. It was about of the meningitis, the chronic otitis media, the presbyacusis, the ototoxicity, the sudden hearing loss, the sound trauma, and the cranial trauma. According to the Table 1, we noted $34.2 \%$ of etiologies related to meningitis and $18 \%$ consecutive to chronic otitis media among children. Among young adult, meningitis was notice in $22 \%$ of cases followed by chronic otitis media in $13.7 \%$ of cases, ototoxicity in $12.5 \%$ of cases and sound trauma in $12.1 \%$ of cases. Finally, presbyacusis represented $55 \%$ of etiologies among elderly. Meningitis, chronic otitis media, presbyacusis, ototoxicity, sudden hearing loss, sound trauma were significantly 
aged-related (Table 1). The different etiologies engendered a sensorineural hearing loss in $76.1 \%$ of cases. A mixed hearing loss in $20.8 \%$ of cases and conductive hearing loss in $2.9 \%$ of cases. The degrees of hearing loss in seven etiologies most frequent were severe and profound in $87.6 \%$ of cases to the right and $82.8 \%$ to the left. They were significant in case of chronic otitis media to the right and in case of sound trauma in the both side (Table 2 and Table 3). The prosthetic pure tonal gain was significant among patient who represented a sound trauma and a sudden hearing loss (Table 4). Concerning the prosthetic speech reception threshold gain, it was significant among patient who represented a presbyacusis and a sudden hearing loss (Table 5). The patients were satisfied, little satisfied and unsatisfied respectively in $68.4 \%, 22.7 \%$ of cases and $8.7 \%$ of cases. The satisfaction as significant in case hearing aid of patient suffering from meningitis, presbyacusis, sound trauma, cranial trauma and sudden hearing loss (Table 6).

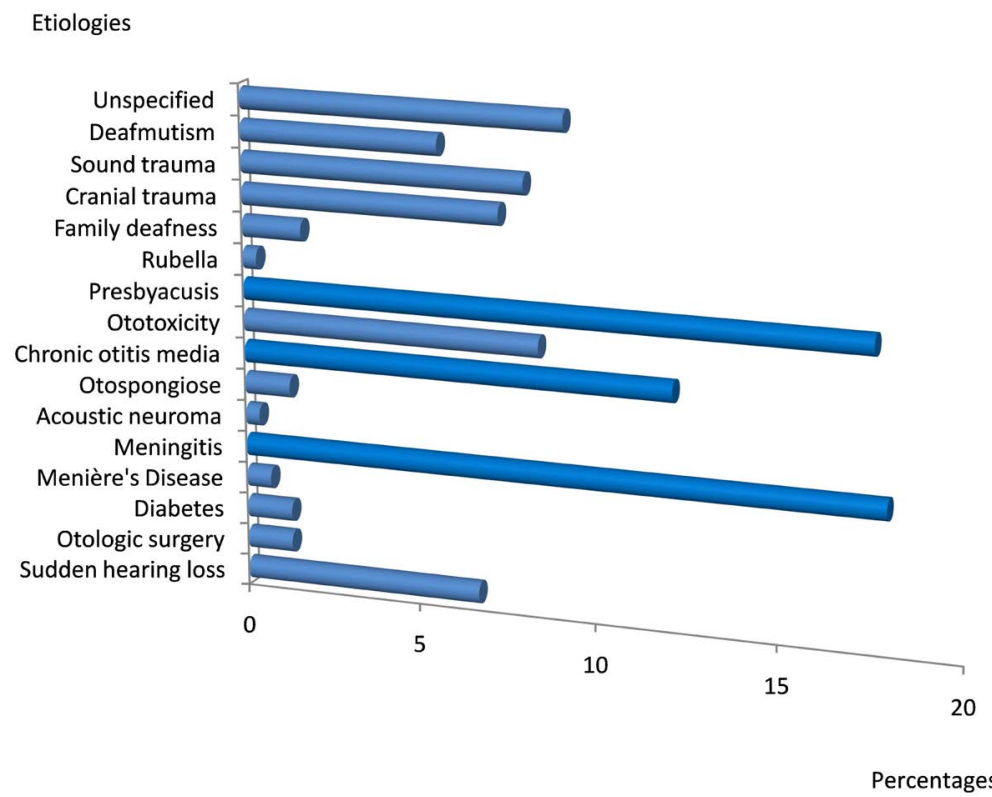

Figure 1. Hearing loss's etiologies.

Table 1. Distribution of etiologies according to the age.

\begin{tabular}{ccccc}
\hline \multirow{2}{*}{ Etiologies } & \multicolumn{3}{c}{ Ages } & \multirow{2}{*}{$\mathrm{P}$} \\
\cline { 2 - 4 } & $\begin{array}{c}0-14 \text { year } \\
\mathrm{n}=117\end{array}$ & $\begin{array}{c}15-49 \text { year } \\
\mathrm{n}=248\end{array}$ & $\begin{array}{c}>50 \text { year } \\
\mathrm{n}=171\end{array}$ & \\
\hline Meningitis & $40(34.2 \%)$ & $55(22.1 \%)$ & $00(0.00 \%)$ & $<0.05$ \\
Presbyacusis & $00(00 \%)$ & $00(00 \%)$ & $94(55 \%)$ & $<0.05$ \\
Chronic otitis media & $21(18 \%)$ & $34(13.7 \%)$ & $10(06 \%)$ & $<0.05$ \\
Ototoxicity & $2(1.7 \%)$ & $31(12.5 \%)$ & $12(0.7 \%)$ & $<0.05$ \\
Sound trauma & $00(0 \%)$ & $30(12.1 \%)$ & $13(07 \%)$ & $<0.05$ \\
Cranial trauma & $4(2.5 \%)$ & $24(9.7 \%)$ & $12(07.6 \%)$ & 0.1 \\
Sudden hearing loss & $2(1.7 \%)$ & $25(10.1 \%)$ & $9(03 \%)$ & $<0.05$ \\
\hline
\end{tabular}


Table 2. Distribution of etiologies according to the right hearing loss.

\begin{tabular}{|c|c|c|c|}
\hline \multirow[b]{2}{*}{ Etiologies } & \multicolumn{2}{|c|}{ right hearing loss } & \multirow[t]{2}{*}{$\mathrm{P}$} \\
\hline & $\begin{array}{l}\text { Mild-Moderate } \\
\qquad \mathrm{n}=80\end{array}$ & $\begin{array}{l}\text { Severe-Profound } \\
\mathrm{n}=443\end{array}$ & \\
\hline Meningitis & $16(2 \%)$ & $80(18.1 \%)$ & 0.76 \\
\hline Presbyacusis & $12(0.15 \%)$ & $83(18.7 \%)$ & 0.42 \\
\hline Chronic otitis media & $5(6.25 \%)$ & $81(18.3 \%)$ & $<0.05$ \\
\hline Ototoxicity & $7(8.8 \%)$ & $55(12.4 \%)$ & 0.40 \\
\hline Sound trauma & $15(18.7 \%)$ & $28(6.3 \%)$ & $<0.05$ \\
\hline Cranial trauma & $7(8.7 \%)$ & $34(7.7 \%)$ & 0.74 \\
\hline Sudden hearing loss & $5(6.25 \%)$ & $27(6.1 \%)$ & 0.95 \\
\hline
\end{tabular}

Table 3. Distribution of etiologies according to the left hearing loss.

\begin{tabular}{|c|c|c|c|}
\hline \multirow[t]{2}{*}{ Etiologies } & \multicolumn{2}{|c|}{ left hearing loss } & \multirow[t]{2}{*}{$\mathrm{P}$} \\
\hline & $\begin{array}{l}\text { Mild-Moderate } \\
\qquad \mathrm{n}=85\end{array}$ & $\begin{array}{l}\text { Severe-Profound } \\
\qquad n=429\end{array}$ & \\
\hline Meningitis & $15(17.6 \%)$ & $81(18.9 \%)$ & 0.78 \\
\hline Presbyacusis & $16(18.8 \%)$ & $78(18.1 \%)$ & 0.88 \\
\hline Chronic otitis media & $05(5.9 \%)$ & $53(12.3 \%)$ & 0.08 \\
\hline Ototoxicity & $7(8.23 \%)$ & $38(8.8 \%)$ & 0.85 \\
\hline Sound trauma & $15(17.6 \%)$ & $28(6.5 \%)$ & $>0.05$ \\
\hline Cranial trauma & $05(5.9 \%)$ & $26(6.1 \%)$ & 0.94 \\
\hline Sudden hearing loss & $6(7.1 \%)$ & $24(12.1 \%)$ & 0.59 \\
\hline
\end{tabular}

Table 4. Distribution of etiologies according to the prosthetic pure tonal gain.

\begin{tabular}{|c|c|c|c|}
\hline \multirow[b]{2}{*}{ Etiologies } & \multicolumn{2}{|c|}{ prosthetic pure tonal gain } & \multirow[b]{2}{*}{$\mathrm{P}$} \\
\hline & $\begin{array}{l}<30 \mathrm{~dB} \\
\mathrm{n}=157\end{array}$ & $\begin{array}{l}>30 \mathrm{~dB} \\
\mathrm{n}=379\end{array}$ & \\
\hline Meningitis & $22(15.9 \%)$ & $71(18.7 \%)$ & 0.44 \\
\hline Presbyacusis & $21(13.4 \%)$ & $73(19.3 \%)$ & 0.10 \\
\hline Chronic otitis media & $20(12.7 \%)$ & $45(11.9 \%)$ & 0.77 \\
\hline Ototoxicity & $18(11.4 \%)$ & $27(7.1 \%)$ & 0.09 \\
\hline Sound trauma & $7(4.5 \%)$ & $36(9.5 \%)$ & $<0.05$ \\
\hline Cranial trauma & $14(8.9 \%)$ & $26(6.9 \%)$ & 0.40 \\
\hline Sudden hearing loss & $5(3.1 \%)$ & $31(8.2 \%)$ & $<0.05$ \\
\hline
\end{tabular}


Table 5. Distribution of etiologies according to the prosthetic speech reception threshold gain.

\begin{tabular}{|c|c|c|c|}
\hline \multirow{2}{*}{ Etiologies } & \multicolumn{2}{|c|}{ prosthetic speech reception threshold gain } & \multirow[t]{2}{*}{$\mathrm{P}$} \\
\hline & $\begin{array}{l}<30 \mathrm{~dB} \\
\mathrm{n}=270\end{array}$ & $\begin{array}{l}>30 \mathrm{~dB} \\
\mathrm{n}=231\end{array}$ & \\
\hline Meningitis & $54(20 \%)$ & $39(16.9 \%)$ & 0.37 \\
\hline Presbyacusis & $36(13.3 \%)$ & $49(21.21 \%)$ & $<0.05$ \\
\hline Chronic otitis media & $30(11.1 \%)$ & $29(12.5 \%)$ & 0.61 \\
\hline Ototoxicity & $27(10 \%)$ & $14(6.1 \%)$ & 0.10 \\
\hline Sound trauma & $19(7 \%)$ & $23(9.9 \%)$ & 0.23 \\
\hline Cranial trauma & $21(7.7 \%)$ & $18(78 \%)$ & 0.87 \\
\hline Sudden hearing loss & $7(2.6 \%)$ & $25(10.8 \%)$ & $<0.05$ \\
\hline
\end{tabular}

Table 6. Distribution of etiologies according to the Satisfaction.

\begin{tabular}{cccc}
\hline & \multicolumn{2}{c}{ Satisfaction } & $\mathrm{P}$ \\
\cline { 2 - 3 } ETIOLOGIES & Not satisfied - little satisfied & Satisfied \\
$\mathrm{n}=170$ & $\mathrm{n}=366$ & \\
Meningitis & $32(18.8 \%)$ & $64(17.5 \%)$ & $<0.05$ \\
Presbyacusis & $19(11.1 \%)$ & $75(20.5 \%)$ & $<0.05$ \\
Chronic otitis media & $22(18.8 \%)$ & $43(11.7 \%)$ & 0.73 \\
Ototoxicity & $19(11.1 \%)$ & $26(7.1 \%)$ & 0.75 \\
Sound trauma & $3(1.7 \%)$ & $40(10.9 \%)$ & $<0.05$ \\
Cranial trauma & $10(5.8 \%)$ & $30(8.1 \%)$ & $<0.05$ \\
Sudden hearing loss & $4(2.3 \%)$ & $32(8.7 \%)$ & $<0.05$ \\
\hline
\end{tabular}

\section{Discussion}

\section{Limits}

It is retrospective study so that we didn't have more information about the history of certains patients. Some hearing loss have not been enough explorated to find the etiology due to the lack of exploration's mean.

The hearing loss of patients worn in the ICHC was essentially acquired hearing loss. The main etiologies were meningitis and presbyacusis. The etiologies were dominated by meningitis and chronic otitis media among children and young adult. The meningitis was significantly related to the children. According to Ag Mohamed [7]. The meningitis represented 54.3\% of etiologies of hearing loss among children and young people of young deaf persons school of Bamako in 1996. It also represents the main cause of hearing loss among children in the western countries. Probably because of the harmful action of toxin bacterial toward the internal ear during the meningitis. This hearing loss can be aggravated in case of central involvement [8]. That underlines the necessity to continue the 
sensitization of population about the importance of prevention of this affection through vaccination. But other studies must be undertaken to determinate if the current meningitis is not due to other bacterial not taken into by current vaccines. The chronic otitis media, the ototoxicity, the sound trauma and the sudden hearing loss were significantly related to the young adult. The after-effect of the chronic otitis media have lead 52\% of sensorineural hearing loss in the Ali's serie [9]. In this affection, the severity of sensorineural hearing loss is function of disease duration. Then it exposes the internal ear to toxin coming from mediator of the inflammation during of the chronic otitis media or ear toxic drop used for a previous treatment. This toxin could penetrate in the internal ear through the round window. They lead an irreversible involvement of bone conduction [10]. Anne heuschkel reported an ascendancy of the sudden hearing loss among old subject (age median 60 years) in his series of 490 patients [11]. The absence of subsidy for the hearing aid, would explain the important number of young people in our series. Then they need all their capacity to find or maintain their job. Among the old subject, the main etiology was the presbyacusis. It represented $30 \%$ within the population of more than 60 years in France [12]. It is the most frequent shape of hearing loss [13]. The increase of its prevalence would be a sign of an increase of the life expectancy. But it favors the social isolation and the depression of the patients. The hearing loss noticed at the ICHC was essentially a severe and profound sensorineural hearing loss. The hearing aid was adapted for the severe hearing loss. But it could be the first step of care in profound hearing loss to allow a hearing stimulation meanwhile setting-up of cochlear implant in the case of deaf-muteness or meningitis. The technical and financial limitations, justified the choice of the hearing aid in the profound hearing loss. We noticed that the prosthetic pure tonal gain was more frequent at patient suffering of hearing loss consecutive to the meningitis and the presbyacusis. But this gain was significant at the patients suffering of sound trauma and sudden hearing loss. The prosthetic speech reception threshold gain was frequent in case of hearing loss secondary to meningitis, presbyacousie, chronic otitis media and sudden hearing loss. This gain was significant only in case of presbyacousie and the sudden hearing loss. It would be a neuronal plasticity tied to the hearing rehabilitation favored by the sound environment maintained by the hearing aid. It would allow a reorganization of neurons coding the zones of hearing in decline due to a lesion of the cochlea. It would allow reactivating these neurones again which would code these zones in decline. This would improve the perception and the hearing discrimination. This neuronal plasticity would be set up faster in case of sudden hearing loss [13]. What would explain why the prosthetic pure tonal gain and the prosthetic speech reception threshold gain were significant in case of sudden hearing loss. The satisfaction of these patients after hearing aid in summer was also significant when at the patients suffering from a hearing loss consecutive to a presbyacusis, an sudden hearing loss and a sound trauma. 


\section{Conclusion}

The main etiologies were the meningitis and the presbyacusis. The prosthetic pure tonal gain and the prosthetic speech reception threshold gain were significant in case of sudden hearing loss. The satisfaction of the patients was significant in case of sudden hearing loss, presbyacusis and of sound trauma. In case of non-satisfaction, we need cochlear implant.

\section{Conflicts of Interest}

The authors declare no conflicts of interest regarding the publication of this paper.

\section{References}

[1] OMS. Surdité et déficience auditive. http://www.who.int/mediacentre/factsheets/fs300/fr/

[2] Babighian, G. and Mazzoli, M. (1989) Prothèse implantable d'oreille moyenne. Résultats cliniques. Cahiers ORL, 31, 3302.

[3] da Silva, L.P.A., Queiros, F. and Lima, I. (2006) Etiology of Hearing Impairment in Children and Adolescents of a Reference Center APADA in the City of Salvador, State of Bahia. Revista Brasileira de Otorrinolaringologia, 72, 33-36.

[4] Stelmachowicz, P.G. and Gorga, M.P. (1998) In: Cummings, C.W., et al., Otolaryngology Head and Neck Surgery, 3rd Edition, Mosby, St. Louis, 401-417.

[5] Natalie, M. and Garabédian, E. (2007) La surdité de l'enfant: Du dépistage à l'appareillage. In: Actualités audio prothétiques. Amplifon, 43, 23-36.

[6] Gelis, C. (1993) Bases techniques et principes d'application de la prothèse auditive. Sauramps médical, Montpellier, 267.

[7] Agmohamed, A., Soumaoro, S., Timbo, S.K., et al. (1996) Surdite de l'enfant en afrique noire: Cas de l'ecole des jeunes sourds de bamako (mali). Médecine d Afrique Noire, 43, 570-573.

[8] Francois, M. and Hamrioui, R. (1997) Dépistage des troubles de, l'audition après une meningite. Journal de Pediatrie et de Puericulture, 10, 454-458. https://doi.org/10.1016/S0987-7983(97)80043-6

[9] Ali Zaidi, S.S., Pasha, H.A., Suhail, A. and Qureshi, T.A. (2016) Frequency of Sensorineural Hearing Loss in Chronic Suppurative Otitis Media. Journal of the Pakistan Medical Association, 66, 42-44.

[10] Luntz, M., Yehudai, N., Haifler, M., et al. (2013) Risk Factors for Sensorineural Hearing Loss in Chronic Otitis Media. Acta Oto-Laryngologica, 133, 1173-1180. https://doi.org/10.3109/00016489.2013.814154

[11] Heuschke, A., Geißler, K. and Boeger, D. (2018) Inpatient Treatment of Patients with Idiopathic Sudden Sensorineural Hearing Loss: A Population-Based Healthcare Research Study. European Archives of Oto-Rhino-Laryngology, 275, 699-707.

[12] Stephane Gallego. Plasticité cérébrale et réhabilitation auditive. https://www.researchgate.net/publication/272644796_Plasticite_cerebrale_et_rehabi litation_auditive_de_la_presbyacousie

[13] Veuillet, E., Gabriel, D., Philbert, B., et al. (2004) Fonctions de la prothèse auditive: Les principaux résultats du groupement de recherche cnrs prothèse auditive audition et prothese auditive. Les cahiers de l'audition, 17, 13-19. 